\title{
The Mean Corpuscular Volume and Hydroxyurea in Brazilian Patients with Sickle Cell Anemia: A Surrogate Marker of Compliance
}

Ana Maria Mach Queiroz ${ }^{1}$, Clarisse Lopes de Castro Lobo ${ }^{1}$, Emilia Matos do Nascimento ${ }^{2}$, Basilio de Bragança Pereira ${ }^{2,3}$, Claudia Regina Bonini-Domingos ${ }^{4}$, Gilberto Perez Cardoso ${ }^{5}$ and Samir K Ballas ${ }^{6 *}$

${ }^{1}$ HEMORIO-State Institute of Hematology Arthur de Siqueira Cavalcanti, Rio de Janeiro, Brazil

${ }^{2}$ Federal University of Rio de Janeiro, COPPE - Postgraduate School of Engineering, Rio de Janeiro, Brazil

${ }^{3}$ Federal University of Rio de Janeiro-School of Medicine, Rio de Janeiro, Brazil

${ }^{4}$ UNESP - Sao Paulo State University, Department of Biology, Hemoglobin and Hematologic Diseases Genetic Laboratory, São Paulo, Brazil

${ }^{5}$ UFF - Fluminense Federal University, Department of Clinical Medicine, School of Medicine, Niterói, Brazil

${ }^{6}$ Cardeza Foundation, Department of Medicine, Jefferson Medical College, Thomas Jefferson University, Philadelphia, PA, USA

\begin{abstract}
The suppression of erythropoiesis by Hydroxyurea (HU) therapy is associated with increase in mean corpuscular volume, in addition to the increase in $\mathrm{Hb}$ F. Monitoring the mean corpuscular volume values and the presence of macrocytosis are effective tools of adherence to the treatment with $\mathrm{HU}$ in patients with sickle cell anemia. The aim of this study is to monitor the mean corpuscular volume values after starting treatment with $\mathrm{HU}$ to determine if macrocytosis can be used as a surrogate marker of compliance with therapy. We conducted a prospective cohort study over one year with measurements of blood counts and mean corpuscular volume after starting therapy with $\mathrm{HU}$ in 95 patients with sickle cell anemia who were regularly followed in our ambulatory outpatient unit. In one-year of successful use of HU the mean value of the mean corpuscular volume increased significantly. The Andersen and Gill model demonstrated that the increase of one unit of MCV implies a $5 \%$ reduction in the risk of visiting the emergency room. Monitoring mean corpuscular volume values after prescribing $\mathrm{HU}$ alerts the provider of noncompliance in order to counsel the patient in question for better adherence to the use of $\mathrm{HU}$ that could improve the quality of care and to reduce morbidity and the frequency of acute pain crises and associated healthcare costs.
\end{abstract}

Keywords: Sickle cell anemia; Hydroxyurea; Compliance; Mean corpuscular volume

\section{Introduction}

Sickle cell anemia (SS) is an inherited chronic inflammatory and degenerative disease in which hemoglobin $\mathrm{S}(\mathrm{Hb} \mathrm{S})$ is produced. Deoxy $\mathrm{Hb} S$ polymerizes and initiates a series of pathophysiologic events including decreased deformability of RBC, vaso-occlusion and tissue damage due to ischemia [1]. The phenotypic expression of the disease varies from mild to severe depending on the specific genotype, gene modifiers, epigenetic and psychosocial factors [2]. In its severe form, the disease is characterized by recurrent acute painful crises, severe anemia and organ damage. The recurrent painful episodes often require treatment in the emergency room or the hospital thus interfering with the quality of life of affected patients [3]. These complications of SS usually manifest themselves around the age of 6 month when the synthesis of the sickle $\beta$ globin chain reaches adult values and continue through the life span of the patient with progressive severity [4-6].

Treatment of patients with SS with Hydroxyurea (HU) has been shown to decrease the frequency of painful crises and acute chest syndrome significantly in addition to other salutary effects such as decreasing mortality and decreasing the frequency of blood transfusion. The exact mechanism of action of $\mathrm{HU}$ is not known although the induction of $\mathrm{Hb} \mathrm{F}$ synthesis and macrocytosis seem to be apparent possible mechanisms [7-10]. Unfortunately compliance with the specific instructions of treatment by the patients has been inadequate. Having an objective marker of compliance by the patients is highly desirable.

The aim of this study is to monitor the Mean Corpuscular Volume (MCV) values after starting treatment with HU to determine if macrocytosis can be used as a surrogate marker of compliance with therapy. A survival model with recurrent events was used to achieve this objective. This model may be used as a tool that allows a multidisciplinary follow-up of the clinical outcome of patients taking HU. This multidisciplinary approach combined with monitoring the MCV values by a physician and a pharmacist will enable a better understanding of the reasons associated with the patients' failure to comply with the prescribed therapy. Moreover, this may generate better approaches to rational use of HU.

\section{Methods}

We evaluated 95 patients with Sickle Cell Anemia (SS) with no coexistent alpha or beta thalassemia who were started on $\mathrm{HU}$ and followed regularly in the outpatient unit, from February 01, 2010 to February 01, 2011. From these patients, 44 (46.3\%) were males and 51 (53.7\%) were females. Their median age at entry was 27 years (mean $31 \pm 13$ ). The age range was 13 to 61 years. They were divided into three age groups: under 26 years ( 43 patients), 26 to 45 years ( 34 patients) and over 45 years (18 patients). All patients were treated with HU $15 \mathrm{mg} / \mathrm{kg} /$ day.

Serum ferritin, folate and B12 were determined by routine

*Corresponding author: Samir K. Ballas, Cardeza Foundation for Hematologic Research, 1020 Locust Street, Philadelphia, PA 19107, USA, Tel: 856-7456380; Fax: 856-795-0809; E-mail: samir.ballas@jefferson.edu

Received August 21, 2013; Accepted September 18, 2013; Published September 21,2013

Citation: Queiroz AMM, de Castro Lobo CL, do Nascimento EM, de Bragança Pereira B, Bonini-Domingos, et al. (2013) The Mean Corpuscular Volume and Hydroxyurea in Brazilian Patients with Sickle Cell Anemia: A Surrogate Marker of Compliance. J Blood Disorders Transf 4: 157. doi: 10.4172/21559864.1000157

Copyright: @ 2013 Queiroz AMM, et al. This is an open-access article distributed under the terms of the Creative Commons Attribution License, which permits unrestricted use, distribution, and reproduction in any medium, provided the original author and source are credited. 
Citation: Queiroz AMM, de Castro Lobo CL, do Nascimento EM, de Bragança Pereira B, Bonini-Domingos, et al. (2013) The Mean Corpuscular Volume and Hydroxyurea in Brazilian Patients with Sickle Cell Anemia: A Surrogate Marker of Compliance. J Blood Disorders Transf 4: 157. doi: 10.4172/2155-9864.1000157

Page 2 of 4

laboratory methods and they were all within normal limits. Complete blood counts, reticulocyte count, lactate dehydrogenase, ALT, AST and serum creatinine were determined twice per month.

\section{Statistical Analysis}

Survival analysis generally assumes that survival times of individuals are independent. However, there are cases where this assumption may not be valid. Studies on individual subjects with recurring events during the observation period show a multivariate survival model. In these situations, it is reasonable to consider that there is dependence between the survival times of each individual. The model usually used to describe a possible association between multiple survival times for each individual is referred to as Frailty which is an extension of the Cox proportional hazards model [11]. In that model, a random effect (frailty) is introduced into the risk function as a multiplicative factor.

Box plots were used in this work to verify the difference between the measured values of the MCV before and after therapy with $\mathrm{HU}$ for each patient.

The Anderson \& Gill (AG) model and the Poisson regression model were evaluated with different outcomes and the same set of covariates [12]. The AG model was used for analysis of recurrent events, where the outcome was the time elapsed until the occurrence of a subsequent ED visit. Three models were considered: the first model used gender, age, the initial MCV and the final MCV as independent variables; the second model used gender, age and the value obtained by the difference between initial MCV and final MCV and the third model used gender, age and the dichotomization of this difference (1 if final MCV is less than initial MCV, 0 if otherwise). The Poisson regression model was also employed to investigate the association between the number of ED visits as the outcome and the initial MCV, final MCV, gender and age as independent variables The implementation was done using the $\mathrm{R}$ Development Core Team software [13].

\section{Results}

During the study there were no significant changes in liver and kidney function tests. In one-year of successful HU use the mean value of MCV changed significantly ( $\mathrm{p}<0.001)$ from 92.76 to 99.77 as shown in Figure 1.

According to the AG model the increase of one unit of MCV implies a $5 \%$ reduction in the risk of visiting the emergency room $(\mathrm{p}<0.001)$. The application of AG model considering the difference between the final MCV and initial MCV as a single explanatory variable (Table 1) confirms the previous result $(\mathrm{p}<0.001)$. Dichotomizing the difference of MCV ( 1 if final MCV is less than initial MCV, 0 if otherwise), the risk of visiting the emergency room is about 3.6 times greater for the group that did not respond to treatment because of the MCV reduction $(95 \%$ $\mathrm{CI}=2.237-5.846, \mathrm{p}<0.001$ ).

All covariates in Poisson model (Table 2) were statistically significant $(p<0.05)$. The Poisson regression model also showed that the increase of one unit in final MCV resulted in a reduction of approximately $6 \%$ in the number of ED visits.

Figure 2 shows Kaplan-Meier estimate and cumulative risk. Patients were divided into two groups, according to treatment response based on the increase in MCV (final MCV>initial MCV) or the decrease in MCV (final MCV<initial MCV). The log-rank, Prentice-Peto and Tarone-Ware tests demonstrated that there is a significant difference $(\mathrm{p}<0.001)$ between the time to next ED visit [14-18].

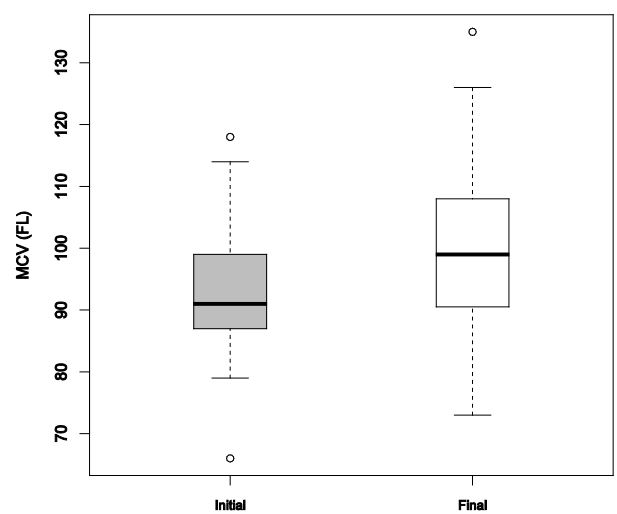

Figure 1: MCV values before and after treatment with hydroxyurea.

\begin{tabular}{|c|l|c|c|c|c|}
\hline \multicolumn{2}{|c|}{} & Estimate & Std.Error & $\mathbf{z}$ & $\operatorname{Pr}(>|\mathbf{z}|)$ \\
\hline Model 1 & MCVini & 0.0248 & 0.0125 & 1.443 & 0.1490 \\
& MCVfin & -0.0511 & 0.0091 & -3.403 & 0.0007 \\
\hline Model 2 & MCVdiff & -0.0518 & 0.0092 & -3.257 & 0.0011 \\
\hline Model 3 & MCVbin & 1.1683 & 0.1590 & 5.088 & $<0.0001$ \\
\hline
\end{tabular}

MCVini=initial MCV; MCVfin=final MCV; MCVdiff=MCVfin - MCVini; $M C V b i n=1$ if final MCV is less than initial MCV, and 0 if otherwise

Table 1: Anderson \& Gill models.

\begin{tabular}{|c|c|c|c|}
\hline Estimate & Std. Error & z value & P Value \\
\hline (Intercept) 0.76 & 0.21 & 3.66 & $<0.001$ \\
\hline MCVdiff -0.06 & 0.01 & -6.38 & $<0.001$ \\
\hline Gender -0.33 & 0.15 & -2.14 & 0.03 \\
\hline Age 0.01 & 0.01 & 2.32 & 0.02 \\
\hline
\end{tabular}

MCVdiff= final MCV - initial MCV

The Poisson regression model was evaluated using the number of ED visits as the outcome and gender, age and the value obtained by the difference between initial MCV and final MCV as independent variables. All covariates in Poisson model were statistically significant $(p<0.05)$. The Poisson regression model showed that the increase of one unit in the positive difference between initial MCV and final MCV resulted in a reduction of approximately $6 \%$ in the number of ED visits

Table 2: Poisson Regression Model.

Figure 3 presents the individual frailty where one can observe that the confidence interval decreases as the risk of visiting the emergency department increases indicating non adherence to HU treatment. This figure was drawn as described previously by Carvalho [19].

\section{Discussion}

Sickle cell disease is an inherited disease affecting 0.1 to $0.3 \%$ of the black Brazilian population. It is estimated that hemoglobin disorders, including thalassemia and sickle cell disease, affect approximately $7 \%$ of the world population [20]. The genetic aspects of the disease, ethnic factors, co-inheritance of polymorphisms, socioeconomic and the cultural reality of Brazil, contribute to the health of these patients. In comparison to other chronic diseases, patients with SCD develop several co-morbidities, including emotional aspects. The physical limitations caused by SCD are sources of emotional stress especially for the carrier of the disease, resulting in difficulties in the educational, emotional and social adjustments [21].

Data from the National Newborn Screening Program in Brazil indicate that the prevalence of sickle cell trait ( $\mathrm{Hb} \mathrm{AS}$ ) is $2-10 \%$. It is estimated that homozygous SS (Hb SS) represents a public health problem in Brazil [22]. Some data report that $25.2 \%$ of children with SCD die before the age of five years if not accurately diagnosed by then. 
Citation: Queiroz AMM, de Castro Lobo CL, do Nascimento EM, de Bragança Pereira B, Bonini-Domingos, et al. (2013) The Mean Corpuscular Volume and Hydroxyurea in Brazilian Patients with Sickle Cell Anemia: A Surrogate Marker of Compliance. J Blood Disorders Transf 4: 157. doi: 10.4172/2155-9864.1000157

Page 3 of 4
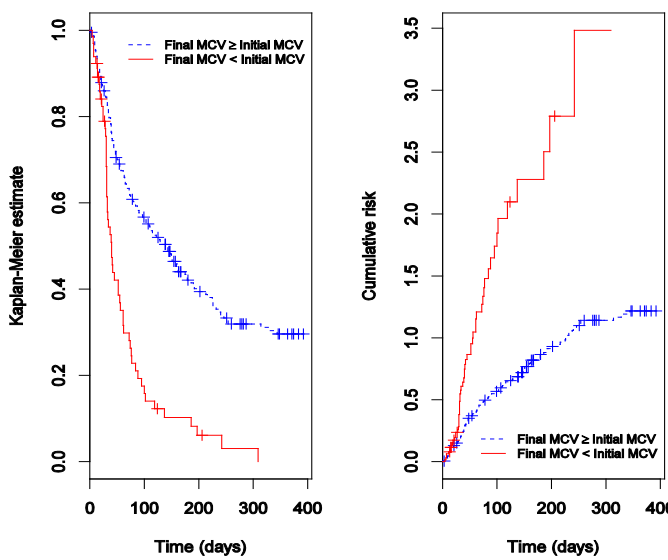

Figure 2: Kaplan-Meier curves, according to treatment response based on the increase in MCV (final MCV>initial MCV). Patients compliant with treatmen instructions return to the emergency room less frequently (left panel) and their risk of having recurrent crises is less than non-compliant patients (right panel) There is a significant difference between the curves in both panels $(p<0.001)$.

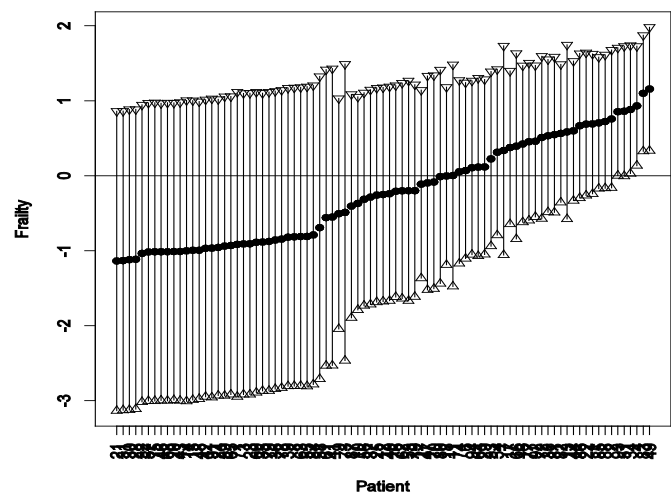

Figure 3: Individual frailty. The y-axis shows the frailty measure (risk of visiting the emergency room) of a non-compliant patient. The distance between the upper-most line and the lowest-most line represents the confidence interval. The solid line shows the increase in the number of visits to the emergency of the patient in question overtime. As the confidence interval decreases, the risk of visiting the emergency room increases significantly.

Early diagnosis and treatment with $\mathrm{HU}$ improves survival and the quality of life of patients with SS [23].

The HU-induced macrocytosis is related to the increase in $\mathrm{HbF}$ $[24,25]$. In some patients, a small increase of 2 to 3 points of MCV was observed after starting HU [26]. The MCV seems to be a good marker for the adherence to the appropriate use of $\mathrm{HU}$ in SS, and can serve as a tool to monitor treatment. The decrease of MCV during treatment demonstrates noncompliance thus alerting the provider that the prescribed medication was not taken according to instructions. Patients who do not use HU properly as indicated by the low MCV values visit the emergency department more frequently and experience more severe pain than those who comply with the prescriber's instructions. The development of tools to monitor adherence is important for the success of therapy. Using the MCV as a monitoring tool is easier, readily available and more cost-effective than other methods. The intake of HU was checked during each outpatient visit using a verbal questionnaire.
In this study we used the MCV values and Anderson \& Gill model as a tool of evaluation for adherence to treatment. The use of this powerful tool in monitoring MCV values after prescribing $\mathrm{HU}$ alerts the provider of noncompliance in order to counsel the patient in question for better adherence to the use of $\mathrm{HU}$ that could improve the quality of care and to reduce social and healthcare costs.

\section{Conclusion}

The MCV proved to be a good marker for the adherence to the correct use of HU in SS and may serve as a tool to monitor treatment. The therapeutic efficacy of $\mathrm{HU}$ is well proven. Patients who do not properly use HU have no significant change in their MCV values and continue to have frequent painful crises.

\section{Acknowledgement}

Supported by the Office of the Secretary of Health for the State of Rio de Janeiro and the Brazilian Ministry of Health

\section{References}

1. Steinberg $\mathrm{MH}$ (2008) Sickle cell anemia, the first molecular disease: overview of molecular etiology, pathophysiology, and therapeutic approaches. ScientificWorldJournal 8: 1295-1324.

2. Gardner K, Bell C, Bartram JL, Allman M, Awogbade M, et al. (2010) Outcome of adults with sickle cell disease admitted to critical care - experience of a single institution in the UK. Br J Haematol 150: 610-613.

3. Benjamin LJ, Swinson GI, Nagel RL (2000) Sickle cell anemia day hospital: an approach for the management of uncomplicated painful crises. Blood 95 1130-1136.

4. van den Tweel XW, van der Lee JH, Heijboer $\mathrm{H}$, Peters M, Fijnvandraat $\mathrm{K}$ (2010) Development and validation of a pediatric severity index for sickle cell patients. Am J Hematol 85: 746-751.

5. Zago MA, Pinto CS (2007) The pathophysiology of sickle cell disease: from the genetic mutation to multiorgan disfunction (in Portuguese). Rev Bras Hemato Hemoter 29: 207-214.

6. Molock SD, Belgrave FZ (1994) Depression and anxiety in patients with sickle cell disease: conceptual and methodological considerations. J Health Soc Policy 5: 39-53.

7. Creary LE, McKenzie CA, Menzel S, Hanchard NA, Taylor V, et al. (2009) Ethnic differences in $\mathrm{F}$ cell levels in Jamaica: a potential tool for identifying new genetic loci controlling fetal haemoglobin. Br J Haematol 144: 954-960.

8. Inati A, Koussa S, Taher A, Perrine S (2008) Sickle cell disease: new insights into pathophysiology and treatment. Pediatr Ann 37: 311-321.

9. Ballas SK, Bauserman RL, McCarthy WF, Castro OL, Smith WR, et al. (2010) Hydroxyurea and acute painful crises in sickle cell anemia: effects on hospital length of stay and opioid utilization during hospitalization, outpatient acute care contacts, and at home. J Pain Symptom Manage 40: 870-882.

10. Tripathi A, Jerrell JM, Stallworth JR (2011) Clinical complications in severe pediatric sickle cell disease and the impact of hydroxyurea. Pediatr Blood Cancer 56: 90-94.

11. Vaupel JW, Manton KG, Stallard E (1979) The impact of heterogeneity in individual frailty on the dynamics of mortality. Demography 16: 439-454.

12. Anderson PK, Gill RD (1982) Cox regression model for counting processes: a large sample study. The Ann Stat 10: 1100-1120.

13. http://www.R-project.org

14. Cox DR (1972) Regression models and life-tables (with discussion). J R Statist Soc B 34: 187-220.

15. Mantel N (1966) Evaluation of survival data and two new rank order statistics arising in its consideration. Cancer Chemother Rep 50: 163-170.

16. Peto R, Peto JA (1972) symptotically efficient rank invariant test procedures (with discussion). J R Statist Soc A 135: 185-207.

17. Prentice RL (1978) Linear rank tests with right-censored data. Biometrika 65 167-179. 
Citation: Queiroz AMM, de Castro Lobo CL, do Nascimento EM, de Bragança Pereira B, Bonini-Domingos, et al. (2013) The Mean Corpuscular Volume and Hydroxyurea in Brazilian Patients with Sickle Cell Anemia: A Surrogate Marker of Compliance. J Blood Disorders Transf 4: 157. doi: 10.4172/2155-9864.1000157

18. Tarone R, Ware J (1977) On distribution-free tests for equality of survival distributions. Biometrika 64: 156-160.

19. Carvalho MS (2011) Análise de sobrevivência: teoria e aplicações em saúde. (2ndedn), Rio de Janeiro: Fiocruz.

20. Loureiro MM, Rozenfeld S (2005) [Epidemiology of sickle cell disease hospital admissions in Brazil]. Rev Saude Publica 39: 943-949.

21. Drotar D (2010) Treatment adherence in patients with sickle cell anemia. $J$ Pediatr 156: 350-351.

22. Felix AA, Souza HM, Ribeiro SB (2010) Epidemiologic and social aspects of sickle cell disease (in Portuguese). Rev Bras Hematol Hemoter 32: 203-208.
23. Ashley-Koch A, Yang Q, Olney RS (2000) Sickle hemoglobin ( $\mathrm{HbS}$ ) allele and sickle cell disease: a HuGE review. Am J Epidemiol 151: 839-845.

24. Nzouakou R, Bachir D, Lavaud A, Habibi A, Lee K, et al. (2011) Clinical followup of hydroxyurea-treated adults with sickle cell disease. Acta Haematol 125 $145-152$.

25. Saleh AW Jr, Velvis HJ, Gu LH, Hillen HF, Huisman TH (1997) Hydroxyurea therapy in sickle cell anemia patients in Curaçao, The Netherlands Antilles. Acta Haematol 98: 125-129.

26. Davies SC, Gilmore A (2003) The role of hydroxyurea in the management of sickle cell disease. Blood Rev 17: 99-109.

Citation: Queiroz AMM, de Castro Lobo CL, do Nascimento EM, de Bragança Pereira B, Domingos CRB, et al. (2013) The Mean Corpuscula Volume and Hydroxyurea in Brazilian Patients with Sickle Cell Anemia: A

Surrogate Marker of Compliance. J Blood Disorders Transf 4: 157. doi: 10.4172/2155-9864.1000157 